\title{
Effect of Solvent Composition on the Critical Micelle Concentration of Cetylpyridinium Chloride in Ethanol-Water Mixed Solvent Media
}

\author{
Ajaya Bhattarai, Sujit Kumar Shah and Ashok Kumar Yadav \\ Department of Chemistry \\ Mahendra Morang Adarsh Multiple Campus \\ Tribhuvan University, Biratnagar, Morant \\ e-mail: bkajaya@yahoo.com
}

\begin{abstract}
The accurate measurement of the specific conductivity of cetylpyridinium chloride in pure water and ethanol-water mixed solvent media containing $0.10,0.20,0.30$ and 0.40 volume fraction of ethanol at room temperature are reported. The concentrations were varied from $\sim 0.005 \mathrm{~mol} \mathrm{l}^{-1}$ to $\sim 0.0002 \mathrm{~mol}^{-1}$.The conductivity of cetylpyridinium chloride decreases with the increase in the volume fraction of ethanol. The critical micelle concentration of cetylpyridinium chloride increases with the increase in the volume fraction of ethanol.
\end{abstract}

Key words: cetylpyridinium chloride, conductivity, critical micelle concentration, ethanol-water mixed solvent media

\section{Introduction}

The chemical structures having suitable solubility properties for surfactant activity vary with the nature of the solvent system to be employed and the conditions of use. In "standard" surfactant terminology, the "head" refers to the solubilizing group - the lyophilic or hydrophilic group, in aqueous systems-and the "tail"'refers to the lyophobic or hydrophobic group in water:

$$
\begin{aligned}
& \mathrm{CH}_{3}\left(\mathrm{CH}_{2}\right)_{\mathrm{n}} \mathrm{CH}_{2}-\mathrm{S} \\
& \text { "tail" "head" }
\end{aligned}
$$

In water, the hydrophobic group may be, for example, a hydrocarbon, fluorocarbon, short polymeric chain, or siloxane chain of sufficient size to produce the desired solubility characteristics when bound to a suitable hydrophilic group. In aqueous systems, the hydrophilic group (the "head") will be ionic or highly polar, so that it can act as a solubilizing functionality.

When surfactants dissolved, after they reach a certain value of concentration, molecules or ions of surfactants begin to associate and to organize themselves into more complex units, also called micelles. In colloidal and surface chemistry, the critical micelle concentration (cmc) is defined as the concentration of surfactants above which micelles form and almost all additional surfactants added to the system go to micelles (IUPAC 1997). The concentration above which micellar aggregates begin to form in a pure surfactant solution is called critical micellar concentration, cmc (Hayakawa \& Kwak 1982).

The determination of $\mathrm{cmc}$ is generally based on the localization of the position of a breaking point in the concentration dependencies of selected physical or chemical properties of surfactant solutions. Because of the surface activity of these substances, measurements of the surface tension of surfactant solutions represent the principal method of cmc determination. However, it is rather tedious and timeconsuming procedure. In the case of ionic surfactants, the utilization of electrochemical measurement is much more convenient, especially the measurements of the electrical conductivity of their solutions with varying concentration. The conductometric method is based on the finding of a breaking point on the curves, which describe the concentration dependence of conductivity. It is well-known, that the conductivity of any solution is directly proportional to the concentration of its ions. The point, where the micelle formation starts, is indicated on the concentration dependence of specific conductivity as a breaking point. The requested value of $\mathrm{cmc}$ is the intercept of two linear functions 
with mutually different slopes.

The presence of alcohols in water will help in breaking down of the water structure. In addition to breaking down the structure of water, alcohols lower down the dielectric constant of the water thereby contributes toward the increase in cmc. An additional complication of alcohol-water mixtures is the possibility of the alcohol to penetrate into the micelle. It is well known that the alcohol molecules orient themselves at the micelle-solvent interface with the hydrocarbon group penetrating slightly into the micelle and the hydroxyl group remaining on the micelle-solvent interface (Emerson \& Holtzer 1967, Miyagishi 1974).

Cetylpyridinium chloride $(\mathrm{CPyCl})$ is a cationic quaternary ammonium compound used in some types of mouthwashes, toothpastes, lozenges, throat sprays, breath sprays, and nasal sprays. It is an antiseptic that kills bacteria and other microorganisms. It has been shown to be effective in preventing dental plaque and reducing gingivitis (Asadoorian 2008). It has also been used as an ingredient in certain pesticides. $\mathrm{CPyCl}$ has also found its use in the washing of poultry products and beef (Bosileval et al. 2004). Although number of works (Varade et al. 2005, Mehta et al. 2008, Parathakkatt et al. 2012) have been done to study cmc of $\mathrm{CPyCl}$ in numerous solvent media in the presence and absence co-ions, such study in ethanolwater mixed solvent media is relatively new. Considering to the importance of $\mathrm{CPyCl}$ this paper deals with the measurement of cmc of $\mathrm{CPyCl}$ in pure water and ethanolwater mixed solvent media corresponding to range of dielectric constant at room temperature (303.15K) by conductometric method.

\section{Methodology}

Ethanol (E. Merck, India) was used for the experimental works. The purified solvent had a density of 0.78097 g. $\mathrm{cm}^{-3}$ and a co-efficient of viscosity of $0.9490 \mathrm{mPa} . \mathrm{s}$ at $303.15 \mathrm{~K}$ these values are in good agreement with the literature values (Lange \& Dean 1967). Distilled water with a specific conductance less than $10^{-6}$ S.cm ${ }^{-1}$ at $303.15 \mathrm{~K}$ was used for the preparation of the mixed solvents. The physical properties of EthanolWater mixed solvents used in this study at $303.15 \mathrm{~K}$ were taken from the published works (Lee \& Lee 1988, Bhattarai \& Sah 2011, Harned \& Owen 1957).

Conductance measurements were carried out on a PyeUnicam PW 9509 conductivity meter at a frequency of
$2000 \mathrm{~Hz}$ using a dip-type cell with a cell constant of $1.15 \mathrm{~cm}^{-1}$ and having an uncertainty of $0.01 \%$. The cell was calibrated by the method of Lind and co-workers (Lind et al.1959), using aqueous potassium chloride solution. The measurements were made at room temperature (303.15K). The details of the experimental procedure have been described earlier (Das \& Hazra 1992, Das \& Hazra 1995). In order to avoid moisture pickup, all solutions were prepared in a dehumidified room with utmost care. In all cases, the experiments were performed in three replicates.

\section{Results and Discussion}

Conductivity measurements of $\mathrm{CPyCl}$ were performed in pure water and water-ethanol mixed solvent media at $303.15 \mathrm{~K}$. The critical micellar concentrations ( $\mathrm{cmc}$ ) of $\mathrm{CPyCl}$ were determined from conductometry. These were obtained from the inflections in the plots of specific conductivity versus surfactant concentration. The data points above and below the inflection were fitted to two linear equations, and the cmcs were obtained from the intersection. This method is found to be reliable and convenient for the present system because of the significant variations of specific conductivity with surfactant concentration in the preand postmicellar regions which allowed us to draw two unambiguous straight lines above and below the $\mathrm{cmc}$. The experimental specific conductivities of $\mathrm{CPyCl}$ as a function of its molar concentration at $303.15 \mathrm{~K}$ of pure water and four different Ethanol-water mixtures (containing $0.10,0.20,0.30,0.40$ volume fractions of ethanol) are depicted in figures 1-5.

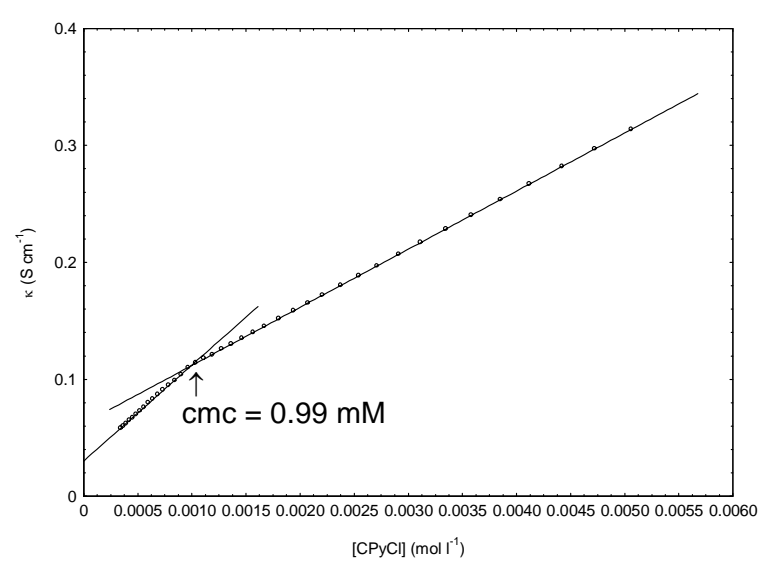

Fig. 1. Specific conductivities of $\mathrm{CPyCl}$ as a function of the surfactant concentration in $303.15 \mathrm{~K}$ : opened circles represent pure water 


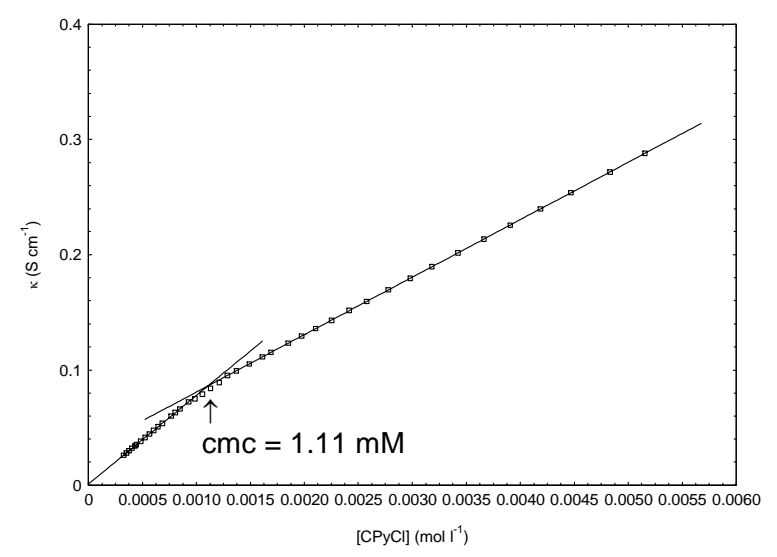

Fig. 2. Specific conductivities of $\mathrm{CPyCl}$ as a function of the surfactant concentration in $303.15 \mathrm{~K}$ : opened squares represent 0.10 volume fractions of ethanol in the solvent mixture

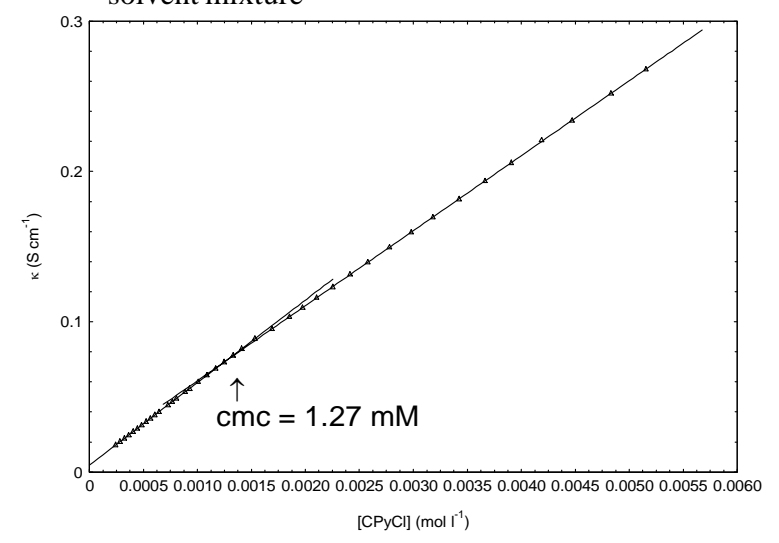

Fig. 3. Specific conductivities of $\mathrm{CPyCl}$ as a function of the surfactant concentration in $303.15 \mathrm{~K}$ : triangles represent 0.20 volume fractions of ethanol in the solvent mixture

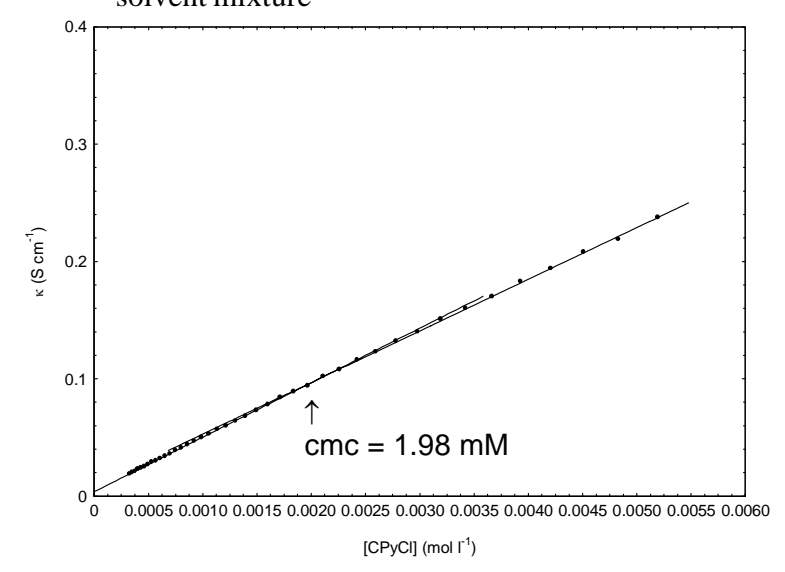

Fig. 4. Specific conductivities of $\mathrm{CPyCl}$ as a function of the surfactant concentration in $303.15 \mathrm{~K}$ : closed circles represent 0.30 volume fractions of ethanol in the solvent mixture

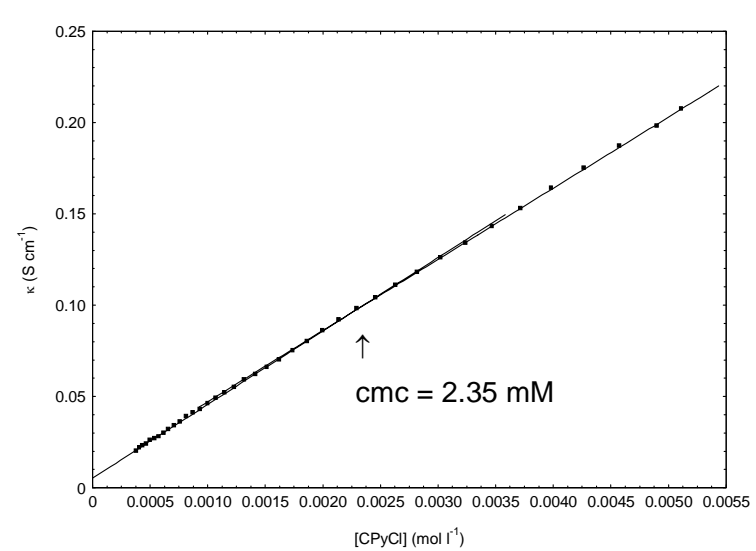

Fig. 5. Specific conductivities of $\mathrm{CPyCl}$ as a function of the surfactant concentration in $303.15 \mathrm{~K}$ : closed squares represent 0.40 volume fractions of ethanol in the solvent mixture

The $\mathrm{cmc}$ of $\mathrm{CPyCl}$ in pure water was found $0.98 \mathrm{mM}$ by Varade et al.2005 at $303.2 \mathrm{~K}$ which also supports to our cmc data of pure water (Table 1). It was also observed that cmc of $\mathrm{CPyCl}$ increase with the increase in the volume fraction of ethanol (Table 1). Similar trend

Table 1. The critical micellar concentratiom (cmc) obtained from conductometry of cetyl pyridinium chloride in pure water and ethanol-water mixed solvent media containing $0.10,0.20,0.30$ and 0.40 volume fraction of ethanol at $303.15 \mathrm{~K}$.

\begin{tabular}{l|l|l|l|l|l}
\hline $\mathrm{T}(\mathrm{K})$ & $\begin{array}{l}\text { Water } \\
\text { cmc } \\
(\mathrm{mM})\end{array}$ & $\begin{array}{l}\text { 0.10volume } \\
\text { fraction of } \\
\text { ethanol } \\
c m c(\mathrm{mM})\end{array}$ & $\begin{array}{l}\text { 0.20 volume } \\
\text { fraction of } \\
\text { ethanol } \\
c m c(\mathrm{mM})\end{array}$ & $\begin{array}{l}\text { 0.30 volume } \\
\text { fraction of } \\
\text { ethanol } \\
c m c(\mathrm{mM})\end{array}$ & $\begin{array}{l}\text { 0.40volume } \\
\text { fraction of } \\
\text { ethanol } \\
c m c(\mathrm{mM})\end{array}$ \\
\hline 303.15 & 0.99 & 1.11 & 1.27 & 1.98 & 2.35 \\
\hline
\end{tabular}

has been observed in experiment related to other surfactant in methanol-water mixed solvent medium (Shah et al.2012). Two factors must be considered to explain this significant influence of ethanol on the $\mathrm{cmc}$ value of CPyCl: (a) the presence of ethanol decreases the cohesive energy density, or the solubility parameter, of water, thus increasing the solubility of the monomeric form of the surfactant and hence the cmc, and (b) the cosolvent causes a reduction in the relative permittivity of the aqueous phase, favouring the mutual repulsion of the ionic heads in the micelle, thus opposing micellisation and increasing the $\mathrm{cmc}$. It 
Nepal Journal of Science and Technology Vol. 13, No. 1 (2012) 89-93

is also well known that addition of solvent which acts as water structure breakers decrease the hydrophobic effect result in to the increase in the cmc value of ionic surfactants (Gracie et al.1996).

The relative permittivity of the medium decreased at a given temperature with the increase in the ethanol content and this trend has also been seen in the conductivity study (Bhattarai \& Raut 2011, Bhattarai and Sah 2011). The conductance decreases with increase of alcohol content for the studied ethanolwater mixed solvent system (Fig. 2-5). The presence of ethanol reduces the dielectric constant of the solvent phase and makes easier for the formation of ion-pairs in the solution phase. In other words, in solvents of low dielectric constants, having small ionizing effect on the electrolytes, the electrostatic forces between oppositely charged ions would be appreciable and conductance value will be small. However, solvents with high dielectric constants yield more conducting solutions.

The following conclusions have been drawn from the above results and discussion. Experimental result for the conductivity of $\mathrm{CPyCl}$ solution in pure water and ethanol- water mixed solvent media has been presented as a function of salt concentration and different percentage composition of ethanol-water mixed solvent media. The cmc of $\mathrm{CPyCl}$ are found to increase with the increase in the volume fraction of ethanol in ethanol-water mixed solvent media.

\section{Acknowledgements}

The authors are thankful to Professor Dr. Sujeet Kumar Chatterjee at the department of Chemistry, Mahendra Morang Adarsh Multiple Campus, Tribhuvan University, Biratnagar, Nepal for the valuable suggestions and discussions. The authors are also thankful to Associate Professor Ghanashyam Shrivastav, the Head of Department of Chemistry, Mahendra Morang Adarsh Multiple Campus, Tribhuvan University, Biratnagar, Nepal for providing us the research facilities to conduct this research work.

\section{References}

Asadoorian, J., and K.B. Williams. 2008. Cetylpyridinium chloride mouth rinse on gingivitis and plaque. J. Dent. Hyg. 82(5):42-42.

Bhattarai, A. and S. K. Sah. 2011. Effects of concentration and relative permittivity on the transport properties of sodium chloride in pure water and ethanol-water mixed solvent media. Res.J.Chem.Sci. 1(6):48-52.

Bhattarai, A. and J. Raut. 2011. Conductometric Studies of Potassium Bromide in pure water and EthanolWater mixed solvent media. J. Alpine Chem., 2: 44-48.

Bosilevac, J., M. Arthur, T. M. Wheeler, T. L. Shakelford, M. Rossman, J. O. Reagan and M. Kooh Maraie . 2004. Prevalence of Escherichia coli O157. Journal of Food Protection 67:646-650.

Das, B. and D. K. Hazra. 1992. Studies on the viscosities, conductances, and adiabatic compressibilities of some tetraalkylammonium perchlorates in 2-Methoxyethanol. Bull. Chem. Soc. Jpn. 65: 3470-3476.

Das, B. and D. K. Hazra. 1995. Conductometric, viscometric, and spectroscopic investigations on the solvation phenomena of alkali-metal ions and Ion pairs in 2Methoxyethanol. J. Phys. Chem. 99: 269-273.

Emerson, M.F. and A. Holtzer. 1967. Hydrophobic bond in micellar systems. Effects of various additives on the stability of micelles of sodium dodecyl sulfate and of n- dodecyltrimethylammonium bromide. J. Phys. Chem. 71 (10): 3320-3330.

Gracie, K., D. Turner and R. Palepu. 1996. Thermodynamic properties of micellization of sodium dodecyl sulfate in binary mixtures of ethylene glycol with water. Can.J.Chem. 74: 1616-1625.

Harned, H.S., and B.B. Owen. 1957. The physical chemistry of electrolytic solutions Reinhold, New York, 234 p.

Hayakawa, K. and J.C.T. Kwak. 1982. Surfactantpolyelectrolyte interactions. 1 . Binding of dodecyltrimethylammonium ions by sodium dextran sulfate and sodium poly(styrenesulfonate) in aqueous solution in the presence of sodium chloride. J. Phys. Chem. 86: 3866-3870.

IUPAC. 1997. Compendium of chemical terminology, 2nd ed. (the "Gold Book"). Compiled by A.D. McNaught and A. Wilkinson. Blackwell Scientific Publications, Oxford. ISBN 0-9678550-9-8.

Lange, N.A., and J.A. Dean. 1967. Lange's Handbook of Chemistry, 10th ed. McGraw-Hill, New York.

Lee, J.J., and M.D. Lee. 1988. Conductance of tetraalkyl ammonium halides in ethanol-water mixtures. Korean J. Chem. Eng. 5(1) : 5-13.

Lind, J.E.Jr., J.J. Zwolenik and R.M. Fuoss. 1959. Calibration of conductance cells at $25^{\circ} \mathrm{C}$ with aqueous solutions of potassium chloride. J. Am. Chem.Soc. 81: 1557-1559.

Mehta, S.K. , S. Chaudhary and K.K. Bhasin. 2008. Selfassembly of cetylpyridinium chloride in water-DMF binary mixtures: a spectroscopic and physicochemical approach. Journal of Colloid and Interface Science 321(2):426-433.

Miyagishi, S. 1974. The effect of organic additives on the Micelle formation of dodecylammonium halides in 
aqueous solutions, Bull. Chem. Soc. Jpn. 47(12): 2972- 2976.

Parathakkatt, S., J. George, S.M. Sankarakutty and L. Sreejith. 2009. Polymer induced structures in cetylpyridinium chloride-octanol micellar system. Journal of Polymer Research 16(5):577-582.

Shah, S.K., T.P. Niraula, A. Bhattarai and S.K. Chatterjee. 2012. A comparative study of critical micelle concentration (CMC) and free energy of micellization $\left(\mathrm{ÄG}_{\mathrm{m}}^{\circ}\right)$ of cationic surfactant (Dodecyltrimethy- lammonium Bromide, DTAB) and anionic surfactant (Sodiumdodecyl Sulphate, SDS) in different composition of methanol-water mixed solvent media by conductometric method at $308.15 \mathrm{~K}$. Bibechana, 8: 37-45.

Varade, D., T. Joshi, V.K Aswal, P.S. Goyal, P.A. Hassan and P. Bahadur. 2005. Effect of salt on the micelles of cetyl pyridinium chloride. Colloids and surfaces $A$ Physicochem. Eng.Aspects 259: 95-101. 
Nepal Journal of Science and Technology Vol. 13, No. 1 (2012) 